\title{
Effect of coppicing on hybrid poplar fine root dynamics
}

\author{
M. Bédéneau and D. Auclair \\ Station de Sylviculture, INRA, Ardon, 45160 Olivet, France
}

\section{Introduction}

Short rotation forestry for biomass production takes advantage of the very strong growth potential of coppice shoots during the first years after coppicing. Growth of the aboveground compartment of coppice has been extensively studied in recent years, but there is a great lack of knowledge concerning the underground system.

Several previnus studies evaluated the structure of large roots in aged coppice. They showed how the root macrostructure can be either used successively at each new rotation, or die and be renewed at each rotation, depending upon the species studied (Bédéneau and Pagès, 1984).

The aim of the present study was to analyze fine root regeneration in relation to coppicing. Root regeneration capacity is indeed linked to the possibility of the tree to store carbohydrate reserves and to use them for aboveground and underground growth after coppicing.

\section{Materials and methods}

Hybrid poplar ( $P$. trichocarpa $x$ deltoides, clone Beaupré) was planted in March 1983 at $2 \times 1 \mathrm{~m}$ spacing and the 3 following treatments were applied, to $800 \mathrm{~m}^{2}$ plots: 11: intensive cultivation (plastic mulch, weeding between rows, fertilization) 1 yr rotation coppice; 13: intensive cultivation 3 yr rotation coppice; E3: extensive cultivation (no weed control, no fertilization) $3 \mathrm{yr}$ rotation coppice.

Root regeneration capacity was studied on 20 stools on each plot, by weighing fine roots newly developed inside $10 \mathrm{~cm}$ diameter soil cores, using the method described by Persson (1978). Small nets were installed in summer 1984 and excavaled twice a year. Newly developed roots were separated into 3 categories ( $<1 \mathrm{~mm}, 1-2 \mathrm{~mm},>2 \mathrm{~mm}$ ), and were weighed (dry). Grass roots were separated from poplar roots.

All treatments were coppiced after the 1985 growing season, 11 for the third time, 13 and E3 for the first time. Aboveground dry woody biomass production and height growth were estimated each year.

\section{Results}

Fig. 1 shows total aboveground and underground biomass production, for the 3 treatments, summarized for each year. The following points can be underlined: 1) One year rotation (I1) had a lower biomass production than 3 yr rotation coppice (13), both for aboveground and for underground parts. However, it was shown that height growth was more vigorous for 11 than for 13 , and that the underground production of grass was lower. 2) Extensive 

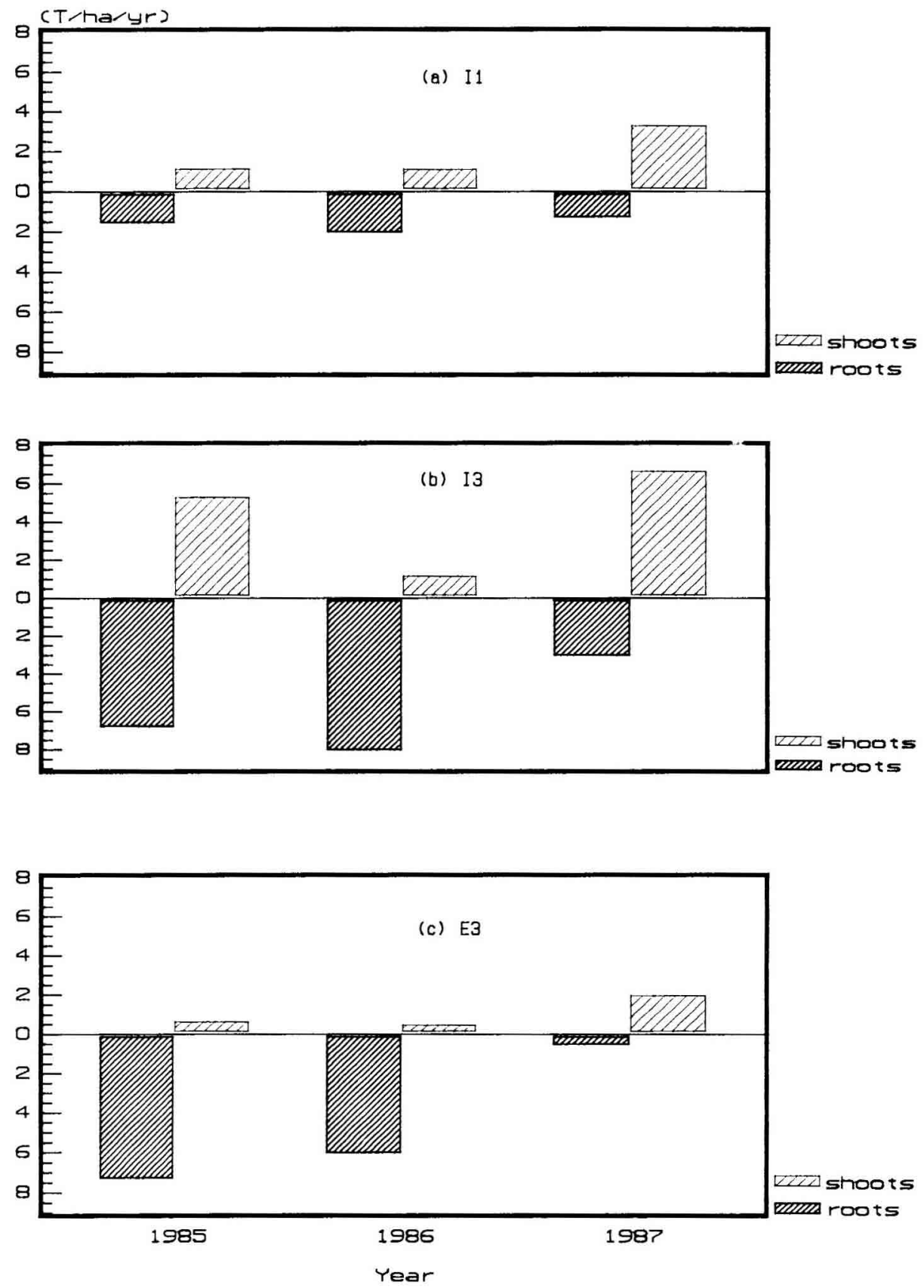

Fig. 1. Aboveground and underground biomass production in poplar coppiced after the 1985 growing season. a: intensive 1 yr rotation; b: intensive 3 yr rotation; c: extensive 3 yr rotation. 
cultivation led to poor aboveground production, but with a vigorous underground production. In addition, grass underground production was very high. 3) Year 1987 was most productive for aboveground parts, for all treatments, but root production was lowest. This was a particularly rainy year, in which the usual summer drought was not observed. 4) In the intensive $3 \mathrm{yr}$ rotation, poplar root production increased after coppicing. Grass root production increased very strongly in extensive cultivation (E3), but poplar root production decreased. 5) The smallest roots, less than $1 \mathrm{~mm}$, accounted for most of the underground production.

\section{Conclusions}

Although these results concern only very short rotations, some indications on root growth of coppice can be gathered.

In the $3 \mathrm{yr}$ rotation, aboveground biomass increment is relativelv low the first year after coppicing, but growth of fine roots is enhanced. Carbohydrate reserves seem to be mobilized preferentially for the growth of fine roots.

In $1 \mathrm{yr}$ rotation, root regeneration is lower than for $3 \mathrm{yr}$ rotation. The amount of reserves may be smaller than for longer rotations.

When adequate water is provided, aboveground biomass production is high, and root growth relatively low, confirming Santantonio and Hermann's findings (1985).

With intensive cultivation, total production, both above- and underground, is higher for the longer rotation.

With extensive cultivation, aboveground production is very low on the studied site. Root growth is relatively high, but grass roots grow very vigorously after the trees are coppiced.

\section{References}

Bédéneau M. \& Pagès L. (1984) Etude des cernes d'accroissement ligneux du système racinaire d'arbress traités en taillis. Ann. Sci. For. 41, 59-68

Persson H. (1973) Root dynamics in a young Scots pine stand in central Sweden. Oikos 30 . 508-519

Santantonio D. \& Hermann R.K. (1985) Standing crop production and turnover of fine roots on dry, moderate and wet sites of mature Douglas fir in western Oregon. Ann. Sci. For. 42, 113-142 